\title{
CIBERCONFIGURAÇÕES PARA A GESTÃO SUSTENTÁVEL DE EXPERIÊNCIAS TURÍSTICAS FOCADAS NO PATRIMÔNIO BIOCULTURAL*
}

\author{
Alfonso González Damián**
}

Resumo: Os objetivos do capítulo são 1) explicar os elementos que caracterizam as configurações cibernéticas da experiência turística e de suas implicações 2) formular recomendações para o gerenciamento sustentável do patrimônio biocultural. Os principais conceitos são a transformação da experiência turística pelo uso das tecnologias da informação e comunicação, a partir de uma perspectiva socioconstrucionista e as implicações práticas que emergem delas, focadas na gestão sustentável do patrimônio biocultural, desde a teoria dos campos de ação estratégica. O capítulo é teórico-conceitual e articula uma perspectiva que começa no microssocial no nível das relações interpessoais e termina no nível mesossocial, que articula as interações entre as coletividades e seu ambiente. São apresentadas recomendaç̃̃es que podem ser úteis para atores sociais no nível local em destinos turísticos cujo interesse é oferecer experiências turísticas focadas no aproveitamento do patrimônio biocultural, quando influenciadas pelas TIC em três configurações cibernéticas: hiperconectividade, realidade aumentada e realidade virtual.

Palabras-chave: Hiperconectividade. Realidade virtual. Realidade aumentada. Gestão da Experiência Turística.

\section{CYBERCONFIGURATIONS FOR THE SUSTAINABLE MANAGEMENT OF TOURISM EXPERIENCES FOCUSED ON BIOCULTURAL HERITAGE}

\begin{abstract}
The objectives of the chapter are 1) to explain the elements that characterize the cyber configurations of the tourist experience, and from their implications 2) to formulate recommendations for the sustainable management of biocultural heritage. The main concepts are the transformation of the tourist experience through the use of information and communication technologies, from a socio-constructionist perspective and the practical implications that emerge from them focused on the sustainable management of biocultural heritage, from the theory of the fields of strategic action. The chapter is mainly theoretical-conceptual and articulates a view that starts from micro-social level of interpersonal relationships and ends at a meso-social level, which articulates the interactions between communities and their environment. Recommendations are presented that can be useful for social actors at the local level in tourist destinations whose interest is offering tourism experiences focused on biocultural heritage, when they are influenced by ICT in three cyberconfigurations: hyperconnectivity, augmented reality and virtual reality.
\end{abstract}

Key words: Hyperconnectivity. Virtual reality. Augmented reality. Management of the Tourism Experience.

\section{CIBERCONFIGURACIONES PARA LA GESTIÓN SOSTENIBLE DE EXPERIENCIAS TURÍSTICAS CENTRADAS EN EL PATRIMONIO BIOCULTURAL}

Resumen: Los objetivos del capítulo son 1) explicar los elementos que caracterizan a las ciberconfiguraciones de la experiencia turística y a partir de sus implicaciones 2) formular recomendaciones para el manejo sostenible del patrimonio biocultural. Los principales conceptos son la transformación de la experiencia turística por el uso de las tecnologías de información y comunicación, desde una perspectiva socioconstruccionista y las implicaciones prácticas que de ellas se desprenden enfocadas a la gestión sostenible del patrimonio biocultural, desde la teoría de los campos de acción estratégica. El capítulo es teórico-conceptual y articula una mirada que inicia en lo microsocial en el nivel de las relaciones interpersonales y culmina en un nivel meso-social, que articula las interacciones entre colectividades y su entorno. Se presentan recomendaciones que pueden ser de utilidad para los actores sociales en el nivel local en los destinos turísticos cuyo interés es ofrecer experiencias turísticas centradas en el aprovechamiento del patrimonio biocultural, cuando seven incididas por las TICen tres ciberconfiguraciones: la hiperconectividad, la realidad aumentada y la realidad virtual.

Palabras clave: Hiperconectividad. Realidad Virtual. Realidad Aumentada. Gestión de la Experiencia Turística.

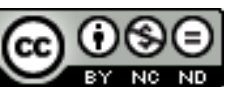

Licenciada por Creative Commons Atribuição Não Comercial / Sem Derivações/4.0/Internacional
* Texto traduzido do original, com a permissão dos autores, por Gabriel Oliveira e Thiago Duarte Pimentel. Revisão técnica: Thiago Duarte Pimentel.

** Doctor en Ciencias Sociales y Políticas/UIA CDMX (2007), Maestro en Administración/UAEMex (1997) y Licenciado en Turismo/UAEMex (1993). Actualmente profesor investigador en la UQROO Cozumel, México. Miembro nivel 1 del Sistema Nacional de Investigadores CONACYT, Miembro de la Academia Mexicana de Investigación Turística y del CECTUR-MD. Líder de Proyecto ETIC México. ORCID: https://orcid.org/0000-0003-4396-0100 [gonzalezd@uqroo.edu.mx] 


\section{INTRODUÇÃO}

Uma vez que as Tecnologias de Informação e Comunicação (TIC), quando utilizadas intensivamente, afectam a experiência turística, produzindo novas configurações espaço-temporais e relações interpessoais, deduz-se que essas novas configurações representam oportunidades e desafios para a gestão sustentável do património biocultural em sítios turísticos.

O patrimônio biocultural, por sua vez, é a base elementar sobre a qual assentam as experiências turísticas e, por conseguinte, requer uma atenção renovada, o que por sua vez conduz a uma ação estratégica por parte dos atores locais nos sítios turísticos.

Nesta linha de ideias, este artigo aborda a resposta a três questões que emergem em relação ao supramencionado: 1) Como se configuram conceitualmente as experiências turísticas em termos de espaço temporais e relacionais induzidas pelas TIC? 2) Quais são as particularidades de tais configurações quando as experiências turísticas estão centradas na utilização do patrimônio biocultural? 3) Quais são as implicações práticas de tais configurações para orientar ações estratégicas no sentido de uma gestão sustentável do patrimônio biocultural a nível local?

Através de um conjunto de reflexões em torno destas três questões, pretende-se alcançar dois objetivos, o primeiro, explicar, do ponto de vista da sociologia construcionista, os elementos que caracterizam as ciber-configurações da experiência turística quando esta se concentra na utilização do património cultural; e segundo, formular o conjunto de elementos para o comportamento estratégico a nível local, dos vários atores envolvidos na gestão sustentável do património biocultural, assumindo as diferentes ciber-configurações da experiência turística.

O contexto a partir do qual as reflexões são formuladas corresponde à experiência do autor, que ao longo de nove anos trabalhando com o tema, principalmente no contexto do México, é proposto em conjunto com um enfoque teórico e, na sequência, exploram-se implicações que podem ser consideradas válidas para o contexto latino-americano. Cabe aos leitores refutar ou confirmar estas reflexões a partir da perspectiva das suas próprias experiências concretas.

Um trabalho reflexivo como o aqui apresentado, encontra justificação na medida em que a maioria da literatura carece de uma visão de construção social da experiência que inclua de forma consistente a comunidade local, o que limita as suas possibilidades de ação resiliente perante o embate das novas tecnologias e do próprio turismo sobre o patrimônio biocultural.

A partir da literatura atual nas principais publicações anglo-saxônicas, também não se explicitam claramente as implicações / transformações espaço-temporais induzidas pelas TIC, apesar de terem sido promovidas como favoráveis aos efeitos da conservação e salvaguarda do patrimônio cultural diante do turismo, apesar do turismo e graças ao turismo. Portanto, é necessária uma visão alternativa, a partir de abordagens teóricas não hegemônicas como é o sócio-construcionismo e também desde os destinos turísticos em territórios que são principalmente receptores de turismo, ou seja, de nações menos desenvolvidas que dependem tanto dos fluxos turísticos internacionais quanto das bonanças do superávit econômico das sociedades emissoras de turistas.

Consequentemente, este artigo focaliza primeiramente a fundamentação teórica das ciberconfigurações induzidas pelas tendências de hipectonectividade $(\mathrm{HC})$, realidade aumentada (AR) e realidade virtual (VR) e se desenvolve conceitualmente suas possibilidades de abordagem a partir do sócioconstrucionismo, na esfera local nos destinos turísticos das sociedades receptoras de turistas, o que é especificamente proposto a partir da teoria dos campos de ação estratégica (TCAE).

A seguir, apresenta-se, a partir de uma reflexão dedutiva, conjuntos de propostas práticas para o uso das TIC em prol de uma gestão sustentável do patrimônio cultural, que pode ser útil tanto para organizações governamentais quanto para os cidadãos em nível local e comunitário.

A fim de desenvolver de forma organizada estes conteúdos, produto da reflexão, o texto foi organizado em quatro partes 1) fundamentação teóricas das ciberconfigurações da experiência turística a partir da sociologia construcionista 2) Metodologia, esta seção explica como a partir da fundamentação teórica se chegou às reflexões sobre as implicações empíricas das ciberconfigurações da experiência turística com apoio na TCAE 3) Particularidades das ciberconfigurações da experiência na gestão do patrimônio biocultural, com alguns exemplos ilustrativos e 4) Reflexões finais como conclusões com futuras linhas de pesquisa. 


\section{QUADROTEÓRICO}

\subsection{Ciberconfigurações da Experiência Turística}

A maior parte da literatura acadêmica sobre turismo carece de uma visão da construção social da experiência que inclui a comunidade local de forma coerente e consistente. A maioria dos estudos sobre a experiência turística referem-se na realidade apenas à experiência do turista e sua visão, socialmente produzida a partir de uma realidade diferente, do que ele visita (Estaregue, et al., González, 2017, Uriely, 2005). Existem algumas obras que vale a pena mencionar que incluem a comunidade local, de forma mais ativa do que o simples fato de fazer parte da paisagem vivenciada pelo turista.

No seu começo, o interesse acadêmico pela experiência turística estava focado na identificação e análise das tipologias de experiências vividas pelos turistas (Boorstin, 1964; Cohen, 1979) e na autenticidade de tais experiências (MacCannell, 1973). Mais tarde, após um ressurgimento do interesse acadêmico pelo assunto, houve uma maior compreensão das experiências dos turistas (Laplante, 1966; Jackson, White e Schmierer, 1996; Prentice, Witt e Hammer, 1998; Wang, 1999 e Small, 1999).

Desde o início deste século, a oferta de experiências turísticas atraentes, satisfatórias, extraordinárias ou memoráveis no setor também significou um interesse renovado em seu estudo, ligando-os a vários aspectos e variáveis do turismo, entre muitos documentos publicados, podemos citar os de Uriely, Yonay e Simchai (2002), Wickens (2002), Quan e Wang (2004), Govers (2005), Obenour, et al. (2006), Jennings e Polovitz (2006), Gelter (2010), Moscardo, (2010), da Costa, et al. (2010), Small e Darcy (2011), Frochot e Wided (2013), Prebensen, Chen e Uysal (2014), De Bruin e Jelinčić (2016), Eide, Fuglsang e Sundbo (2017), Gardiner e Scott (2018), Calleja e Gonzalez, 2018; Bec, et al. (2019), He, et al. (2019) e Vada, et al.

De fato, a produção acadêmica em torno do tema tem sido tão profusa que já existem trabalhos abundantes focados em revisões, reorientações e precisões sobre as formas e maneiras necessárias para investigá-lo em profundidade, algumas delas, as de Lengkeek (2001), Ryan (2002), Uriely (2005), Oh, Fiore e Jeoung (2007), Jurowski (2009), Morgan, Lugosi e Ritchie (2010), Sharpley e Stone (2011 e 2012), Elands e Lengkeek, (2012), Liu, Li e Xiao
(2013), Tussyadiah (2014), Kim (2014), Adhikari e Bhattacharya (2016) e Estaregue 2017).

Apesar do fato de ter havido um incremento significativa na quantidade de pesquisas desta natureza, nos últimos 10 ou 20 anos, poucos estudos recentes abordam a idéia de que a experiência é também um produto da interação entre pessoas, entre turistas (Lin, et al, 2019; Sfandla e Bjork, 2012; Zgolli e Zaiem, 2017), mas também entre turistas e anfitriões, em um processo que tem sido chamado de co-criação das experiência, seja entre a marca e o consumidor (Campos, et al., 2015; Prahalad e Ramaswamy, 2004), ou entre pessoas anfitrionas e turistas (Ellis, et al., 2017; Gonzalez, 2017b, 2018a e 2018b; Majboub, 2014; Sugathan e Ranjan, 2019).

A experiência turística pode ser entendida, para os fins deste documento, desde uma perspectiva socioconstrutivista, como um produto da relação intersubjetiva durante um longo período de tempo em que tanto os anfitriões quanto os turistas assumem tais papéis, entre muitos outros possíveis, a fim de definir cada situação em um quadro apropriada (González, 2017b). Ambos os papéis como os quadros são, por sua vez, construções sociais objetivadas através de gerações, mas que são reconstruídas, reinterpretadas cada vez que uma situação particular de interação é definida (Berger e Luckman, 1967; Goffman, 1986; González, 2009). Esta perspectiva permite considerar tanto turistas quanto anfitriões, além de incorporar a coletividade em uma abordagem micro-social, o que, entre outras coisas, permitirá equilibrar a importância de ambos os papéis na produção da experiência (González, 2018).

Além do acima exposto, também não não foram claramente levantadas na literatura acadêmica, com clareza as implicações e transformações espaçotemporais e relacionais que induzem as tecnologias de informação e comunicação-TIC (Bogicevic, et al, 2019; Boksberger e Akinsola, 2011, González, 2017a e 2018; Neuhofer, Buhalis e Ladkin, 2014; Tussyadiah e Fesenmaier, 2009), apesar de que é precisamente seu surgimento o que tem estimulado o interesse no estudo da construção de experiências turísticas nos últimos anos.

Dado que as experiências humanas são construídas a nível cerebral e em grande parte são socialmente, a partir da atribuição de significado aos contextos particulares aprendidos em um determinado contexto sócio-cultural (Berger e Luckmann, 1967), a presença de dispositivos e 
inovações tecnológicas no mundo contemporâneo os transformou substancialmente. Três tendências podem ser identificadas nas transformações: 1) a hiperconectividade como elemento constitutivo das experiências turísticas atuais, 2) a realidade aumentada para o desenho de novas experiências turísticas e 3) a realidade virtual como um desenho integral das experiências turísticas e meta-turísticas.

A hiperconectividade, entendida como é proposto pela CISCO (2015 e 2016), supõe uma condição na qual as pessoas vivem em um estado de acesso permanente às redes de informação e comunicação através do uso de vários dispositivos portáteis ou não e sua infinidade de aplicações, na medida em que se tornam não apenas uma possibilidade, mas uma necessidade (Egger, 2010). Dentro deste quadro de referência, o acesso às redes de internet e telefônicas são hoje em dia praticamente uma necessidade para os viajantes, na medida em que, se não forem acessíveis, podem passar de um pequeno inconveniente a um obstáculo intransponível que arruina a experiência de viagem (Wang e Fesenmaier, 2013). Isto não é raro, já que os cafés e restaurantes mais populares nos locais visitados pelos turistas não são necessariamente populares pela alta qualidade de seus produtos ou serviços, mas por oferecerem acesso wifi gratuito (Buhalis e Law, 2008; Buhalis e O'Connor, 2005).

Os viajantes hoje se envolvem em suas viagens, por meio dos dispositivos, desde o planejamento, a través de uma infinidade de aplicações que o permitem participar ativamente do desenho de sua experiência, desde os locais a visitar, as atividades a realizar, o planejamento do itinerário, as reservas de transporte, acomodações e outros serviços assistidos pelos aparelhos, desde um universo de aplicações tão especializadas que permitem até decidir como organizar a bagagem, o que comprar antes da viagem e até o grau do protetor solar que será necessário dependendo do local a visitar e da previsão do tempo. A conectividade permite acessar informações sobre 0 lugar visitado, compará-las com outros lugares, fazer reservas e modificar aquelas já feitas (Boksberger e Akinsola, 2011; Okazaki, et al., 2015; Sheldon, 2004).

Da mesma forma, o viajante, durante a viagem, pode se conectar com seu ambiente habitual, com os conhecidos que não o acompanharam durante a viagem, com o trabalho, com a coletividade, com suas comunidades de referência, etc. Tal conexão leva a uma sensação nem sempre consciente de estar aqui e ali simultaneamente ou quase simultaneamente (Dickinson, et al., 2014; Jansson, 2007; Wang e Fesenmaier, 2013). Se está no lugar onde viajou e ao mesmo tempo está com aqueles que não viajaram, eles também estão lá e não estão, eles compartilham as vivencias através dos comentários, locais, posts, fotos, vídeos, animações, tweets, snaps e muitas outras aplicações (Wang e Xiang, 2012; Wang, Xiang e Fesenmaier, 2016). A selfie ao mesmo tempo que é uma prova de estar em outro lugar, permite compartilhar com os outros à essa outra parte e, portanto, torna-se habitual, se conecta com os outros.

Em geral, a conectividade com o espaço habitual atenua a experiência de alteridade ou do diferente, exceto quando a conexão é perdida ou deliberadamente desligada. Perder a conexão deixa o viajante indefeso diante da alteridade, o devolve ao tempo em que ele devería se cuidar ou se aventurar, deixar-se perder, distanciar-se de outros habituais e talvez encontrar-se a si mesmo. Tudo isso é tão forte que hoje só se suporta por curtos períodos off-line. Um efeito indireto desta reconfiguração é que o prestador de serviços se afasta e até desaparece da simultaneidade, passando às vezes de co-produtor a ator secundário na experiência turística, um ator secundário no contexto da experiência (Goffman, 1986). Além disso, uma vez terminada a viagem, a hiperconectividade continua transformando a experiência vivida, o viajante pode reviver a viagem através de várias aplicações que lhe permitem relatála, escrever suas experiências, avaliá-las, recomendálas ou compartilhar suas opiniões com outros viajantes potenciais, sejam eles conhecidos ou não (Tussyadiah e Fesenmaier, 2009).

Se a hiperconectividade reconfigura os tempos e espaços da experiência dos viajantes e prestadores de serviços em seu papel de turistas e anfitriões, os torna mais distantes, mediados e assíncronicos, multiplicando-os e fragmentando-os, um impacto ainda maior pode ser visto com tecnologias de virtualização: a realidade virtual e a realidade aumentada. No jargão tecnológico, realidade aumentada é a aplicação de vários dispositivos e ferramentas tecnológicas para incorporar objetos, pessoas, condições, características virtuais em espaços ou situações nas quais eles não estão realmente presentes (Kounavis, et al., 2012).

Na realidade aumentada, a experiência é projetada para alterar o tempo e o espaço de forma deliberada, não mais para aproximar o viajante do 
habitual, mas para aproximá-lo de uma realidade que não é, que talvez foi ou será, ou que é de ângulos inacessíveis ou de pontos de vista que excedem as capacidades humanas. Nela busca-se enriquecer a experiência "melhorando" o que já existe nos locais visitados, é a indústria do turismo, que projeta a seu gosto a experiência para torná-la atraente, em muitos casos mesmo quando ela perde autenticidade, se distancie da própria identidade e se posicione em uma espécie de identidade idealizada para o visitante, ou seja, elaborada para esse fim.

Na experiência turística aumentada, o turista recebe mais do que a realidade bruta pode the oferecer, é claro que o turista sabe disso, ele entende que a realidade aumentada não é "como realmenteé", mas como "poderia ter sido", como "pode ser", como "gostaríamos que fosse", talvez "mais autêntica do que a realidade como ela é". A experiência turística aumentada é a imaginada, a suposta, a confiável, socialmente construída e co-produzida em cumplicidade com a indústria, a partir de quadros não necessariamente compartilhadas com outros atores (Goffman, 1986).

Será desnecessário dizer que o que é aumentado está centrado naquilo que se deseja aumentar e, portanto, diminui aquilo que se deseja ignorar, evitar ou eliminar, portanto não é muito exato considerá-lo como uma experiência enriquecida, em qualquer caso seria enriquecido apenas em um certo sentido. $\mathrm{Na}$ realidade virtual, a experiência abandona completamente a realidade real e está localizada em outra não "real", nela o viajante recebe, estímulos não reais de desfrute de experiências que não estão lá, portanto não é necessário viajar para outros lugares para ser um viajante (Guttentag, 2010; Huang, et al., 2015).

No plano puramente cerebral não há diferença entre realidade real e realidade virtual, desde que esta última seja sensorialmente indistinguível da primeira, não haveria razão para vivenciá-las de forma diferente. Hoje eles ainda estão em desenvolvimento, mas oferecem possibilidades que já são surpreendentes, os designers e programadores da experiência não precisam mais ser atores como tais, eles são produtores, mas já estão muito distantes da interação com o usuário da experiência.

A oferta de virtualização pode, no entanto, fazer parte daquelas que são vividas durante uma viagem, caso em que seriam ou são, de fato, complementares às experiências reais. Por exemplo, jantar com os ricos e famosos, ou hospedar na melhor suíte do melhor hotel, etc. As combinações que já são oferecidas hoje de experiências turísticas hiperconectadas, com realidade aumentada e momentos de realidade virtual (veja quadro 1), fazem das viagens de hoje verdadeiras transgressões ao plano espaço-temporal convencional.

Quadro 1. Ciberconfigurações da experiência turística incidida pelas tendencias tecnológicas.

\begin{tabular}{|c|c|c|}
\hline Ciberconfiguração & Efeitos no espaço-temporal & Efeitos na interação social \\
\hline $\begin{array}{l}\text { Hiperconectividade } \\
\text { (HC) }\end{array}$ & $\begin{array}{l}\text { Origem e destino se aproximam graças à } \\
\text { comunicação instantânea. } \\
\text { O turista fica conectado durante sua viagem } \\
\text { com amigos, familiares e comunidades que } \\
\text { o acompanham virtualmente. } \\
\text { A comunicação em tempo real também } \\
\text { reduza percepção do tempo. Exceto quando } \\
\text { a conexão é perdida, o tempo tende a } \\
\text { parecer expandido e vazio. }\end{array}$ & $\begin{array}{l}\text { A interação está se tornando cada vez mais mediada } \\
\text { entre as pessoas, mas ao mesmo tempo mais } \\
\text { inclusiva e coletiva. O viajante seleciona com quem } \\
\text { interagir, tornando a experiência menos dependente } \\
\text { da presença síncronica dos anfitriões e mais } \\
\text { dependente os meios e dispositivos (IoT). } \\
\text { A informação agregada e analisada (big data) permite } \\
\text { a criação de experiências personalizadas mesmo a } \\
\text { nível individual. }\end{array}$ \\
\hline $\begin{array}{l}\text { Realidade } \\
\text { Aumentada (RA) }\end{array}$ & $\begin{array}{l}\text { As experiências podem ser vividas em } \\
\text { lugares inacessíveis ou vistas de lugares } \\
\text { impensáveis. } \\
\text { As informações que complementam a } \\
\text { experiência real podem mostrá-la em } \\
\text { estados temporários diferentes do atual. }\end{array}$ & $\begin{array}{l}\text { A indústria do turismo escolhe os elementos da } \\
\text { realidade a aumentar, de forma que condiciona a } \\
\text { experiência do viajante. } \\
\text { Uma vez que a RA requer dispositivos de mediação, } \\
\text { ela tende a diminuir a necessidade de interação } \\
\text { síncronica entre anfitriões e turistas. }\end{array}$ \\
\hline Realidade Virtual (RV) & $\begin{array}{l}\text { A experiência pode ser oferecida em um } \\
\text { lugar diferente do representado. } \\
\text { Experiências de viagem no tempo ou para } \\
\text { locais inacessíveis de outra forma tornam-se } \\
\text { possíveis. }\end{array}$ & $\begin{array}{l}\text { Quem vive a experiência escolhe a realidade virtual } \\
\text { que deseja vivenciar, os detalhes são objeto de } \\
\text { desenho da indústria, que tende a ser menos } \\
\text { turística. A interação entre turistas e anfitriões torna- } \\
\text { se totalmente virtual. }\end{array}$ \\
\hline
\end{tabular}

Fonte: Elaboração propria. Uma versão anterior deste quadro se publicou em González (2017b). 
O aqui não é mais apenas aqui, mas múltiplos "aqui", o agora também não é apenas agora, mas um então com múltiplos "agora", a interação é fragmentada e multiplicada entre viajante-não viajante, anfitrião-não anfitrião, a experiência segue sendo co-produzida, mas a interação simultânea entre os atores não é mais uma exigência. O viajante é acompanhado por aqueles que ele sabe que não estão lá ou estão apenas parcialmente, ele é atendido por aqueles que ele sabe que não estão lá ou estão apenas parcialmente ou como atores secundários em uma encenação (Goffman, 1986) na qual ele participa convencido, parcial ou virtualmente convencido de que está vivendo uma experiência que o afasta parcialmente de seu ambiente habitual (veja a Quadro 1).

Estas três tendências têm um impacto diferenciado nas coordenadas espaço-temporais e de interação, razão pela qual serão chamadas neste documento de ciberconfigurações da experiência turística mediada pelas TIC, ou brevemente ciberconfigurações. Em suma, são a ciberconfiguração da hiperconectividade, a c. da realidade aumentada e a c. da realidade virtual. Podem se apresentar e na verdade o fazem, de uma forma mista na prática real do turismo. Ou seja, existem experiências turísticas que dependem tanto da hiperconectividade quanto da realidade virtual, ou que combinam elementos de realidade aumentada com hipeconectividade, mas a diferenciação aqui é de interesse em termos acadêmicos para facilitar sua análise.

As várias ciberconfigurações têm então implicações práticas para a indústria do turismo, tanto em termos de gestão de destinos turísticos quanto para os anfitriões e turistas, que hoje se deparam com a necessidade de atender a essas múltiplas configurações da realidade, tanto a ciber-realidade como a realidade-realidade.

Analisar estas implicações em detalhes excederia em muito as possibilidades de alcançá-lo dentro dos limites de um artigo, assim se optou por um caminho, que faz parte das linhas de pesquisa e trabalho do autor deste trabalho: as implicações que estas ciberconfigurações têm em um nível prático na gestão sustentável de experiências centradas no patrimônio biocultural. Para examinar as implicações, será utilizada a Teoria dos Campos de Ação Estratégica (Fligstein e McAdam, 2012), que por sua vez se fundamenta no conceito de campo de Bourdieu (Bourdieu e Wacquant, 1992). Os detalhes sobre as razões e a forma como é abordada em um marco sócio- construcionista são apresentados na seção de metodologia.

Uma das preocupações práticas mais urgentes nos destinos turísticos é a necessidade de encontrar um equilíbrio entre o uso e a conservação do patrimônio natural e cultural disponível no nivel local (Cheer and Lew, 2018). A história tem nos mostrado que o uso excessivo que se transforma em exploração inevitavelmente esgota os recursos e danifica irreversivelmente o patrimônio tanto no âmbito do ecossistema quanto no da obra humana (WCED, 1987).

O turismo tem desempenhado um papel importante neste dilema, pois, por um lado, são estes recursos patrimoniais que tornam um local atraente e, portanto, incentivam a demanda turística, mas, ao mesmo tempo, seu desgaste ou uso abusivo levam a um efeito oposto, repulsivo e, portanto, des-incentivam a demanda (Muñoz, Fuentes e Fayos-Solà). Em vista desta condição, foi levantada a necessidade de que as atividades turísticas que são realizadas em contato direto com bens patrimoniais, naturais e culturais, em um grupo hoje chamado patrimônio biocultural, sejam geridos com foco na sustentabilidade (Agnoletti e Rotherham, 2015; Gavin, et al., 2015).

Sob tais premissas, nos destinos turísticos, as experiências são desenhadas, produzidas e oferecidas centradas no uso turístico do patrimônio biocultural, focalizadas em atrair visitantes que procuram especificamente tais experiências em maior ou menor grau, como principal motivação para sua viagem, dando origem ao chamado turismo cultural e de natureza. Os turistas que procuram este tipo de experiências específicas também tendem a demonstrar interesse na conservação e no uso sustentável do patrimônio (Du Cros e McKercher, 2015), de modo que sua participação na co-criação das experiências é intensificada

\subsection{Abordagens Alternativas}

Neste sentido, se juntam aos atores relevantes para a gestão das experiências, desde seu desenho, produção, comercialização e até mesmo sua execução e avaliação. Estes processos de gestão, portanto, devem ser conduzidos com a participação do grupo de atores relevantes, uma vez que demonstram interesse tanto no uso quanto na conservação do patrimônio biocultural, constituindo campos estratégicos de ação (Fligstein e McAdam, 2012) nos quais as decisões são tomadas. 
Estes campos são construções sociais, que surgem diretamente da interação entre os atores relevantes para o campo em si, não são entidades formais, embora pudessem sê-lo, e operam somente com base na existência de algum valor no qual os atores estejam interessados. Dentro destes campos, são estabelecidas hierarquias e estruturas, assim como regras de ação, que não são necessariamente dadas por escrito, mas são conhecidas pelos atores no campo (Fligstein e McAdam, 2011).

Em cada um dos campos que surgem na prática, associados aos bens patrimôniais bioculturais, participam tanto membros de governos locais, como a iniciativa turística privada, os próprios turistas, como outros atores relevantes, como produtores agrícolas, artistas e artesãos, autoridades do setor cultural e ambiental, iniciativa privada que aproveita recursos naturais ou culturais, entre muitos outros (Salazar, González e Macías, 2020).

A participação de múltiplos atores, cada um com seus próprios interesses e agendas, naturalmente torna a tomada de decisões para a gestão de experiências turísticas mais complexa mesmo quando não foram reconfiguradas pelo uso intensivo das TIC. A seção final deste capítulo apresenta as reflexões sobre o que emerge quando as ciberconfigurações são introduzidas de forma mista.

\section{METODOLOGIA}

A análise das implicações das ciberconfigurações da experiência turística a nível prático em sua gestão sustentável quando focalizada no patrimônio biocultural é o resultado de um exame dedutivo das informações obtidas através de múltiplos estudos de caso e com base em várias metodologias ao longo de nove anos no contexto do México.

Destes, se extrae e se reflete sobre o conjunto de implicações que as configurações da experiência turística têm a nível local quando se trata de desenhar, planejar, implementar e avaliar ações estratégicas para a gestão sustentável do patrimônio biocultural.

Para a análise das implicações práticas das ciberconfigurações em cenários concretos, foi necessário recorrer a uma proposta teórica que, por um lado, fosse compatível com a orientação sócioconstrucionista das abordagens que fundamentam a própria idéia das ciberconfigurações da experiência turística, desenvolvidas a partir de uma posição interpessoal, em escala micro-social e, por outro lado, introduzisse elementos para compreender o comportamento estratégico dos atores sociais em um âmbito local, no qual os atores poderiam ao mesmo tempo ser indivíduos ou entidades coletivas, localizados em uma escala mesocial.

Esta proposta teórica é precisamente a Teoria dos Campos de Ação Estratégica (TCAE) desenvolvida pelos norte americanos Neil Fligstein e Doug McAdam (2011 e 2012) com a idéia de "expor uma teoria integrada que explicasse como a estabilidade e a mudança são alcançadas pelos atores sociais em arenas sociais circunscritas" $(2012,3)$. Sua teoria se baseia em três componentes principais, o primeiro é que ela considera os campos de ação estratégica como o bloco estrutural básico da vida política e organizacional na economia, na sociedade civil e no estado.

O segundo componente é a noção de que todo campo está inserido em um ambiente maior que inclui outros campos de maneira dinâmica, em constante transformação. O terceiro componente é a ideia de que os atores sociais inseridos mantêm a ordem em um determinado campo, com base no que eles chamam de habilidades sociais, entendidas como "as capacidades de pensamento e ação intersubjetivas que moldam o fornecimento de sentido, interesses e identidade a serviço de fins coletivos" $(2012,4)$.

Esta forma de conceber os campos está em grande parte endividada com o trabalho de Bordieu e Wacquant (1992), acrescentado com as reflexões dos próprios autores (Fligstein, 1996 e 2001; McAdam, 1982) e as obras de Martin (2003) e DiMaggio e Powell (1983). Embora seja então parcialmente influenciada por uma tradição estruturalista, sua concepção coletiva da construção de habilidades sociais, os campos e ambiente dos campos, também a posiciona na tradição sócio-construcionista, compatível com os conceitos de construção social da experiência turística a partir da interação de atores em quadros de referência que se produzem ao longo do tempo e do espaço, que foram levantados aqui e em trabalhos anteriores (González, 2017b e 2018).

Assim, a TCAE fornece diretamente as categorias que permitirão refletir sobre as implicações práticas das três ciberconfigurações (HC, AR e VR) sobre as habilidades sociais dos atores envolvidos, os campos de ação estratégica e suas transformações, e o ambiente dos campos de ação estratégica. Os resultados das reflexões, ligados na medida do possível a casos e situações a título de exemplo, são apresentados a seguir. 


\section{CIBERCONFIGURAÇÕESDA EXPERIÊNCIATURÍSTICA CENTRADA NO PATRIMÔNIO CULTURAL:}

O patrimônio biocultural em um local específico, além de qualquer definição acadêmica, na esfera local, é uma construção social. Os bens do patrimônio natural ou cultural e as expressões culturais consideradas como patrimônio imaterial, de uma comunidade qualquer, podem ser considerados como tal para os próprios membros da comunidade, desde que haja um interesse consciente de que seu valor seja conservado e que seja suscetível de continuar sendo assim através de gerações.

Esta consideração, seja ela uma ação deliberada para sua conservação, ou simplesmente uma expressão de preocupação por sua possível perda, é suficiente para que ela seja coletivamente, comunitariamente distinguida como patrimônio biocultural. Em outras palavras, em sua origem, o patrimônio biocultural é patrimônio biocultural para a comunidade local, independentemente de ser ou não para atores externos, inclusive turistas.

Ao mesmo tempo, existem expressões culturais, edifícios, espaços, paisagens, espécies, ecossistemas ou espaços em geral em qualquer comunidade que poderiam ser considerados importantes do ponto de vista de atores externos, incluindo os turistas, que a partir de perspectivas construídas a partir de contextos sócio-culturais externos, poderiam ser considerados autênticos ou valiosos em si mesmos, quer constituam uma atração para turistas ou simplesmente que para pessoas fora da comunidade constituam elementos representativos de identificação do local visitado ou do que se acredita sobre ele. Estas apreciações não coincidem necessariamente com a visão local e, portanto, não podem, a priori, ser consideradas como referindo-se ao patrimônio biocultural.

É claro, a partir desta primeira reflexão, que não necessariamente coincide $\mathrm{o}$ que a partir das subjetividades de cada grupo de pessoas, pode ser considerado como patrimônio biocultural. No entanto, sem perder de vista esta realidade, são apenas as manifestações da natureza e do trabalho humano que são consideradas valiosas para a comunidade e para os visitantes que deveriam ser consideradas como parte das experiências turísticas centradas no patrimônio biocultural de um destino turístico.

Em cada comunidade, o patrimônio biocultural é valorizado por seus integrantes, mas o valor atribuído a ele não é o mesmo para todos os membros da comunidade, na verdade, este valor tende a ser acumulado por alguns atores com especial interesse nele.

As partes interessadas em relação a um determinado valor formam os chamados campos de ação estratégicos (Fligstein e McAdam, 2012), entendidos como conjuntos de relações entre atores, individuais ou coletivos, que seguem as regras estabelecidas entre eles para obter, acumular e compartilhar um determinado valor. Portanto, são atores relevantes para fins de gestão de experiências turísticas focalizadas no patrimônio biocultural, representantes dos setores público, privado e social da comunidade anfitriã no destino turístico, assim como representantes dos turistas (Salazar, González e Macías, 2020).

A partir da interação que estes atores têm com o objeto de seu interesse em alguma manifestação específica do patrimônio biocultural, formam-se os campos de ação estratégica, a cargo daqueles que realizam a gestão das experiências turísticas, desde seu planejamento e desenho, sua implementação, oferta e avaliação, particularmente quando se propõe, a busca de uma gestão sustentável.

Por sua vez, as ciberconfigurações das experiências turísticas, previamente delineadas, têm implicações diretas tanto sobre as habilidades sociais dos atores participantes em cada campo, quanto sobre a conformação estratégica e o funcionamento do próprio campo e sobre a relação do campo com seu ambiente. Neste sentido, a seguir se apresenta um conjunto de reflexões que estas implicações exigem em termos de ações estratégicas para a gestão do patrimônio biocultural, que os campos, os atores sociais que neles participam, assim como em geral os destinos turísticos em escala local, enfrentam, o que pode ser útil para organizações governamentais, empresariais ou cidadãs em nível local e comunitário (Cheer and Lew, 2018; Eide, et al., 2017).

\subsection{Ciberconfiguração da Hiperconectividade}

No caso da configuração da hiperconectividade, os consumidores de experiências turísticas têm à sua disposição e praticamente na palma de suas mãos, a possibilidade de contrair o espaço e o tempo para desfrutar de experiências cada vez mais exóticas, mas ao mesmo tempo mais abrigados pela própria vida cotidiana, isto thes permite aproximar-se de experiências culturalmente mais distantes ou mesmo proibidas ou socialmente não aceitas ou aceitáveis. 
Em relação às habilidades sociais, a relação tempo-espacial transformada induzida pelas TIC destaca a necessidade de que os atores desenvolvolvam suas habilidades de comunicação aproveitando as novas tecnologias. E também treinamento tanto para visitantes quanto para todo o conjunto das partes interessadas, especialmente no uso de aplicações próprias, desenvolvidas para fortalecer a comunicação e a conectividade no destino, especialmente aquelas utilizadas para a coleta de informações com enfoque "Big data".

No mesmo âmbito das habilidades sociais, no que diz respeito às interações reconfiguradas pelo impacto das TIC, um aspecto de grande importância no campo da gestão sustentável do patrimônio biocultural é a possibilidade de incentivar comportamentos próambientais e pró-conservação através da simples presença de dispositivos de vigilância interconectados (Tussyadiah e Miller, 2019). A aplicação de tecnologias para acelerar o movimento nos aeroportos, sem perder a segurança, tem sido levada ao extremo, por exemplo, no Aeroporto Internacional de Dubai, onde as informações biométricas dos viajantes são controladas de forma rápida e automatizada (Hans, 2014).

A possibilidade de manter em permanente conexão com outros estimula a criatividade dos turistas (Gretzel e Jamal, 2009), o que possibilita novas formas de interação entre anfitriões e visitantes mediadas pela tecnologia que pode muito bem estar focada na colaboração ativa na conservação do patrimônio, ao mesmo tempo em que responde a motivações de auto-expressão, enriquecimento da própria experiência, de conexão social ou envolvimento com comunidades virtuais (Wong, et al., 2019). De fato, estimula o aprendizado de outros costumes e cultura pelos turistas (Li, et al., 2019).

De fato, as experiências turísticas enriquecidas pela tecnologia estimulam os processos de co-criação da mesma experiência (Neuhofer, et al., 2014), especialmente quando ela se torna interativa, imersiva e persuasiva, em suma, empoderada, o que pode levar diretamente aos esforços para conservar e utilizar de forma sustentável o patrimônio biocultural.

Em relação à reconfiguração dos campos de ação estratégica em termos espaço-temporais como resultado da $\mathrm{HC}$, se encontra na utilização possibilitada pela grande quantidade de informações coletadas e analisadas através das redes, permitindo aos gestores de destinos turísticos e de sítios de patrimônio biocultural realizar uma melhor gestão em tempo real
(Buhalis, 2003). Também introduz novos interessados potenciais (conectados através dos turistas) no campo de ação estratégica.

Da mesma forma, esta intensa conectividade e fluxo de informações digitais leva às possibilidades de análises big data, o que permite não apenas personalizar as experiências turísticas em nível praticamente individual, mas também em termos de gestão, permite planejar os usos temporais e espaciais do patrimônio biocultural, ajustando a oferta e a demanda em tempo real e reduzindo as pressões desnecessárias em temporadas e momentos de maior demanda (Garay, 2019).

Quanto à reconfiguração das interações no nível dos campos de ação estratégica, a necessidade de que elas sejam realizadas de forma síncronica é reduzida, ou seja, muitas interações podem ser realizadas de forma mediada, incentivando uma gestão otimizada. Isto também reduz a necessidade de certos postos de trabalho que tendem a ser realizados por dispositivos e aplicações interconectadas. A este respeito, se modifica a percepção de risco e a confiança que os turistas em particular podem ter em empresas, marcas, produtos ou instituições (Currás, et al., 2017; Korstanje e George, 2015). Um exemplo de aplicação neste sentido é o chamado "C5" na Cidade do México, - Centro de Comando, Controle, Informática, Comunicações e Contato Cidadão, que realiza o monitoramento em vídeo das ruas e praças da cidade, integra o serviço de chamadas de emergência 911 e de denúncia anônima permanentemente ao longo do dia e do ano (Governo da Cidade do México, 2020).

Uma condição para que os benefícios da hiperconectividade apareçam é, naturalmente, a relevância de oferecer e manter a conectividade suficiente para o desfrute dos consumidores, contar com as condições tecnológicas é um assunto que deve ser tratado colaborativamente, para o bem da comunidade, pelos atores participantes em cada campo de ação estratégica. Na verdade, é previsível que os atores que controlam o acesso à tecnologia se tornarão rapidamente atores empoderados.

Em relação ao ambiente dos campos, em termos de reconfigurações espaço-temporais induzidas pela $\mathrm{HC}$, o reconhecimento de que os turistas têm contato imediato com seus amigos e familiares que não estão fisicamente com eles no destino torna-se um canal de comunicação direto e possivelmente muito eficaz em termos de marketing do destino, mas ao mesmo tempo se torna um espaço altamente competido, 
somente as empresas que apreciam as oportunidades oferecidas pelas TIC administrarão seus recursos com sucesso a fim de enriquecer suas inovações e aumentar sua competitividade no futuro (Buhalis e O'Connor, 2005).

Este ambiente supõe, portanto, um imperativo para os atores envolvidos nos campos de ação estratégica, visando à atenção das necessidades individualizadas dos visitantes, para integrar todos os elementos da cadeia de produção e inovação (Buhalis e Direito, 2008). Além de colaborar entre organizações no nível de destino para tirar proveito das vantagens e reconhecer-se como aliados e não como concorrentes.

Esta tendência leva sistematicamente aos chamados destinos turísticos inteligentes, um exemplo disso é o programa espanhol Red de Destinos Turísticos Inteligentes (Red DTI, 2020).

\subsection{Ciberconfiguração da Realidade Aumentada}

A realidade aumentada permite que a informação digital seja conectada à realidade, ou seja, o conteúdo disponível nas redes se torna acessível através de dispositivos focados no ambiente natural e cultural. É de certa forma, dar um passo adiante na hiperconectividade, para colocá-la no mundo da vida cotidiana e, portanto, também no mundo dos destinos turísticos. A reconfiguração a que ela conduz tem implicações práticas para os lugares turísticos.

Em primeiro lugar, em relação às habilidades sociais e aos efeitos da transformação espaçotemporal da RA, afeta a necessidade dos atores envolvidos em cada campo de ação estratégica de conhecer mais detalhadamente a história do patrimônio biocultural, a fim de expô-lo mais de perto à realidade, uma vez que isso incentiva a conexão entre o turista e o lugar visitado (Jung e Han, 2014).

A presença de tecnologias de realidade aumentada permite reafirmar os espaços e tempos do local turístico que não deveriam ser acessíveis, seja por sua fragilidade ou pela dificuldade associada ao risco de acesso, o que por sua vez tem um impacto no incentivo ao comportamento pró-ambiental e pró-conservação.

No aspecto da interação e habilidades sociais, uma vez que as tecnologias de realidade aumentada não utilizam apenas recursos visuais, mas multisensoriais (Keckes e Tomicic 2017), há uma necessidade de desenvolver estas habilidades entre os atores participantes, incluindo tanto os anfitriões quanto os turistas.
Dado que o patrimônio biocultural pode ser mostrado de uma forma muito mais completa e detalhada aos turistas através de tecnologias de realidade aumentada, é necessário um maior conhecimento da cultura e dos valores dos turistas para que o que é mostrado não seja apenas atraente e persuasivo, mas livre de violência e discriminação acidental devido à falta de conhecimento do Outro.

Um exemplo praticamente disponível para todos das tecnologias de realidade aumentada são os aplicativos de smartphone para encontrar lugares próximos à localização atual do usuário. Essas aplicações, embora pareçam ser totalmente objetivas e transparentes, obedecem a toda uma série de algoritmos que, por sua vez, levam ao viés da forma de pensar da maioria de seus usuários. Isso torna necessário que nos campos de ação estratégica, os atores participantes tomem consciência disso e, mesmo quando não é seu objetivo, tenham o cuidado de rever o funcionamento dessas tecnologias e influenciar sua apresentação adequada, respeitosa e não violenta.

Quanto à incidência da ciberconfiguração da RA nos campos de ação estratégica locais, nos aspectos espaço-temporais, ela permite fazer uma seleção de temporadas de mercado, y de lugares para passeios e/ou experiências, ao favorecer a ativação/desativação temporária de certos conteúdos, o que implica que é necessário um planejamento muito detalhado do uso do espaço, tanto ao longo de cada dia da semana como por ano por temporadas. Isto afeta diretamente a necessidade de envolver historiadores, arqueólogos, geneticistas, antropólogos, biólogos e cientistas em geral no campo de ação estratégica. A RA oferece às empresas valor agregado em sua comercialização, incentivando novas visitas ou recomendações dos locais visitados (Özkul e Kumlu, 2019).

Quanto à interação no campo de ação estratégica em sua reconfiguração pela RA, sabe-se que os visitantes estão dispostos a pagar mais quando esta tecnologia é utilizada em museus (He, et al., 2018) e parques naturais, o que leva à possibilidade de projetar novas experiências enriquecidas, com maiores características sócio históricas e naturais do destino turístico e ao desenvolvimento de aplicações deste tipo de tecnologia. Um exemplo da aplicação desta tecnologia é o caso da zona arqueológica de Teotihuacán, México (Hyundai Motor México, 2020).

Com relação às implicações da ciberconfiguração RA no ambiente dos campos de ação estratégica, no 
espaço temporal, o ambiente não envolve mais apenas o tempo presente, mas também inclui o passado e o futuro, tanto virtualmente como em termos do ambiente de outros destinos turísticos com ofertas similares que enriquecem, mesmo de forma personalizada, aproveitando a análise big data, as informações sobre um site (Kounavis, et al 2012 e Özdemir e Kllıç, 2018).

Esta condição abre possíveis espaços de disputa de "experiências originais" e "apropriação cultural" no ambiente dos campos, diante dos quais será necessário ter não apenas instrumentos, mas também estratégias de ação.

A reconfiguração das interações no ambiente dos campo como resultado da RA, dado que se sabe que seu uso correto pode ajudar na conservação de sítios frágeis dentro de espaços patrimoniais (Xiao, et al., 2018 e Özdemir e Kilıç 2018), tende a se tornar uma exigência de mercado e, num futuro próximo, objeto de certificações e selos de qualidade, o que forçará os sítios turísticos, mesmo aqueles relutantes, a investir nestas tecnologias. Um exemplo encorajado pelo governo é o projeto desenvolvido para o estado de Oaxaca, México (CONACYT, 2015).

Figura 1: Teotihuacan, México.

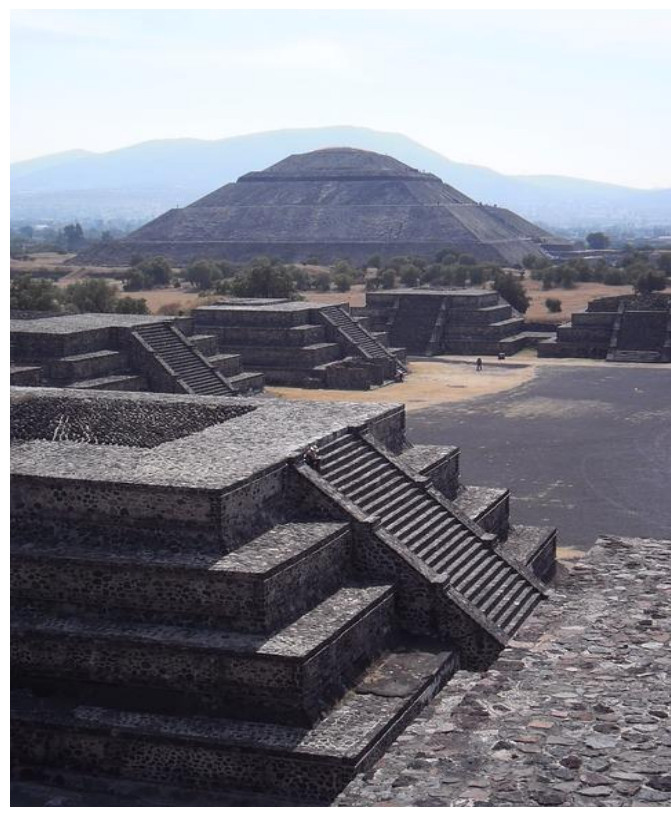

Fonte: Imagem de seonghyeon em Pixabay.

\subsection{Ciberconfiguração da Realidade Virtual}

A tecnologia da realidade virtual permite aos usuários fazer uma imersão com efeitos em vários ou todos os sentidos em uma realidade criada inteiramente no mundo digital, mas que chega o mais próximo possível e até um pouco mais, da realidade. Estas tecnologias abstraem o usuário da realidade e em termos gerais requerem instalações e equipamentos adequados para que a abstração e a imersão sejam realizadas de forma segura e controlada.

Para os locais turísticos, permite-lhes oferecer aos visitantes experiências do local em momentos diferentes do atual ou apreciá-lo a partir de perspectivas fisicamente inacessíveis ou cujo acesso tenha sido restrito. Isto é especialmente útil, por um lado, para que os usuários com algum tipo de deficiência possam desfrutar de sua visita ao destino, de modo que locais inacessíveis ou restritos tenham menos pressão real e também façam parte da experiência do turista.

Com relação às habilidades sociais dos atores nos campos de ação estratégica, há uma clara necessidade de desenvolver maior conhecimento sobre o próprio patrimônio, assim como desenvolver habilidades na interpretação contextual da realidade do próprio destino em tempos passados. O desenvolvimento e aplicação destas tecnologias de forma planejada para influenciar a redução do comportamento perigoso dos turistas dependerá disto (Teisl, et al., 2018).

Envolver os próprios turistas no desenvolvimento dessas habilidades através de sua participação em jogos de design-play-experience (DPE) incentiva o respeito por locais ameaçados e frágeis (Coghlan e Carter, 2020), que são característicos do patrimônio biocultural, já que as pessoas mais dispostas a adotar a tecnologia são mais influenciadas pela VR do que aquelas que não o são, mas finalmente a imersão na RV produz uma sensação de bem-estar que é mais relevante do que a autenticidade da mesma (Kim e Hall, 2019). Este tipo de tecnologia pode ser encontrado em visitas virtuais a museus, sítios arqueológicos e parques e monumentos naturais. Como exemplo, a visita virtual ao Museu Regional de Guanajuato, México (INAH, 2012).

Em relação às interações no âmbito das habilidades sociais, sabe-se que a tecnologia RV pode ser usada como um gatilho para a emotividade na experiência (Martins, et al., 2017), que enriquece a experiência visitante desde que o usuário tenha um senso de controle, participação, eficácia, curiosidade, vibração, associação temporal e prazer (Wei, et al., 2019) e que da melhores resultados quando se refere a uma motivação hedônica (Kim, et al., 2019). 
Neste sentido, enfatiza-se a necessidade de que o desenho de experiências de realidade virtual seja realizado de forma consciente, com a participação não só dos especialistas em desenvolvimento tecnológico como tal, mas também dos próprios membros do campo de ação estratégica, que teriam que ser treinados para manter uma comunicação efetiva com os tecnólogos, de modo que seja a visão local e privilegiando o patrimônio biocultural que prevaleça sobre os critérios puramente técnicos deste tipo de desenvolvimento.

Um dos principais efeitos da tecnologia RV é que ela minimiza a interação sincrônica tanto entre anfitriões e turistas, quanto em relação ao próprio espaço patrimonial, o que permite e exige uma hiperespecialização das funções a serem cumpridas pelos anfitriões, que estão mais envolvidos em tarefas de gestão do que em servir o turista.

No que diz respeito à incidência da configuração da RV nos campos de ação estratégica no local de destino turístico, sabe-se que a RV incentiva a visita real aos locais turísticos, pois gera a sensação de presença real que fortalece a preferência por um determinado destino (Tussyadiah, et al., 2018), o que possibilita oferecer experiências em todos os momentos, mesmo que não seja a temporada ideal e localizadas em praticamente qualquer lugar do destino, incluindo áreas perigosas ou inacessíveis para algumas pessoas ou para todos os visitantes. Essas condições implicam na necessidade de envolver os conhecedores do destino, mas também os desenvolvedores de tecnologia, nos campos de ação estratégica.

\section{Figura 2. Pirâmide de Kukulkán en Chichén Itzá, México.}

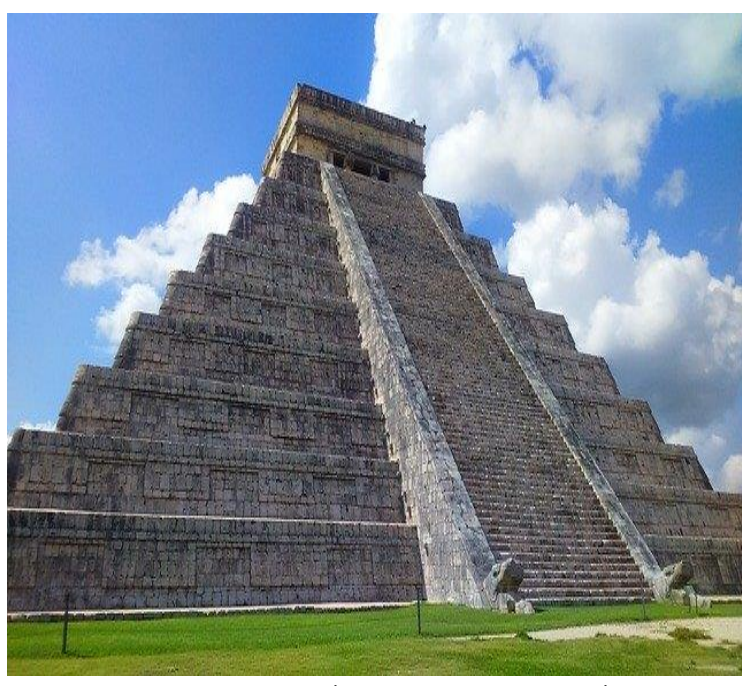

Fonte: Imagem de Jimena Soto en Pixabay.
Apesar de toda tecnologia exigir, a RV em particular exige maiores investimentos em equipamentos, instalações e treinamento, bem como na produção de tipo cinematográfico e de software para melhor apresentar o destino, para testar e ensaiar com visitantes reais e potenciais e para sempre afinar as experiências virtuais para obter seus efeitos positivos de uma forma sensível ao destino turístico.

Em termos das interações no campo de ação estratégica, esta tecnologia tem um impacto direto na redução da interação tanto de turistas quanto de anfitriões com patrimônio biocultural frágil, delicado, danificado ou seriamente ameaçado, tornando possível planejar o uso do patrimônio de forma a privilegiar sua conservação. Um exemplo do uso deste tipo de tecnologia é a visita virtual à pirâmide de Kukulkan em Chichén Itzá, considerada maravilha do mundo, que por razões de conservação fechou o acesso dos visitantes ao próprio monumento (INAH, 2020).

A influência da ciberconfiguração da RV no ambiente dos campos de ação estratégica, em termos do espaço temporal, é conhecida por influenciar o desejo de visitar um lugar, mas de forma mais lenta e profunda, com maior respeito, quando se fala de nostalgia e apego emocional (Lin, et al, 2020), que seu uso pode ajudar na conservação de sítios frágeis dentro de espaços patrimoniais (Xiao, et al., 2018 e Guttentag 2010) e também pode influenciar a escolha de uma marca específica (Bogicevic et al. 2019; Lee, et al., 2019), bem como consolidar uma imagem de destino (Govers, 2005).

Isto implica que o ambiente dos campos de ação estratégicos se torna muito mais competitivo e que as decisões relativas à RV podem influenciar o destino, mesmo que não sejam tomadas ali. Não se deve descartar o fato de que a RV tem a capacidade real de inibir o desejo de realmente viajar para destinos turísticos, já que as experiências virtuais podem muito bem substituí-la por competir com experiências de viagem virtuais mais emocionais e realistas ou mesmo percebidas como mais autênticas do que as reais.

Além da possibilidade, já real, de oferecer visitas a locais fisicamente inacessíveis para a humanidade de hoje, como a visita virtual que a NASA oferece em Marte (NASA, 2017), ou a viagem virtual no tempo para visitar os momentos de auge da história da humanidade.

Finalmente, em termos das interações transformadas pela RV no ambiente dos campos, 
sabe-se que a RV é mais poderosa do que apenas a informação online para estimular a visitação (Zeng, et al., 2020) e que atrai tanto os usuários com maior aceitação da tecnologia como aqueles que não o fazem (Huang, et al., 2015), tornando a interconexão com outras ofertas e destinos não apenas necessária, mas estratégica para locais turísticos que oferecem experiências de patrimônio biocultural.

Figura 3. Mars Rover da NASA.

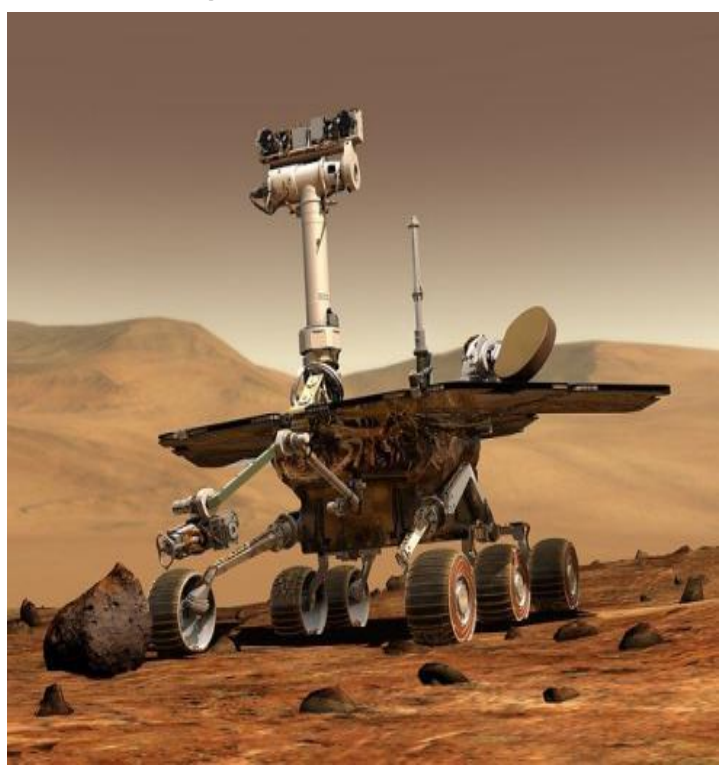

Fonte: Imagem de Wikilmages em Pixabay.

\subsection{As Configurações Eletrônicas e seu Impacto na Estrutura dos Campos de Ação Estratégica}

As ciberconfigurações da experiência turística têm conseqüências inegáveis sobre a estrutura dos campos de ação dos atores sociais envolvidos, ou seja, introduzindo elementos de valorização que se o desenvolvimento tecnológico não interviesse, não existiriam nas relações em geral e especialmente nas relações de poder entre os diferentes atores sociais. Como declarado por Fligstein e McAdam (2012), a existência de interesses em relação a uma fonte de valor também gera um campo no qual são estabelecidas regras não escritas para obter e acumular tal valor, o que também gera diretamente diferenças na distribuição de poder e tendências de acumulação por parte de alguns atores em relação a outros. No caso de cada uma das ciberconfigurações, é evidentemente o valor da própria tecnologia que é introduzida e estimula a conformação dos campos de ação estratégica ao seu redor, nos quais os atores com maior acesso ao controle do valor da tecnologia, por sua vez, adquirem uma posição vantajosa em relação aos demais, vantagens que são transferidas para outros campos das relações sociais, como os de poder, simbólicos e particularmente econômicos.

Neste sentido, pode-se observar, após uma primeira análise, que, embora seja o valor da própria tecnologia que seria fundamental no interesse dos atores para alcançar seu controle sobre outros atores, em cada uma das três ciberconfigurações da experiência podem ser esperadas certas diferenças. No caso da ciberconfiguração do $\mathrm{HC}$, aqueles atores que conseguem controlar a infra-estrutura para facilitar a conectividade terão, sem dúvida, uma vantagem sobre outros que se deslocam diretamente para o controle das relações de poder e benefício econômico, o que, sendo atores fora das comunidades locais, obviamente será em seu detrimento.

Por outro lado, para a ciberconfiguração da AR, apesar de ser a existência da tecnologia que reconfigura as relações, ela é basicamente a base do que "é aumentado", que em si mesmo tem o valor, neste sentido, os atores que conseguem controlar os bens patrimoniais bioculturais serão também aqueles que terão a possibilidade de obter uma vantagem sobre os outros e, provavelmente, transferir essa vantagem para outros campos, como os do poder político, simbólico ou econômico. É nesta ciberconfiguração que a desapropriação ou apropriação por pessoas de fora das comunidades locais de bens do patrimônio biocultural é duplamente negativa, pois além da desapropriação em si, isso lhes daria uma vantagem, provavelmente incontestável, sobre os atores locais.

Finalmente, no caso da ciberconfiguração da RV, dado que a tecnologia permite uma desconexão completa do espaço local, é na qual a própria tecnologia virtualizada, seja ela aplicações de software ou desenvolvimentos mistos de software de hardware, consegue concentrar o maior valor, de modo que os atores que a desenvolvem ou conseguem ganhar controle sobre ela, adquiram uma vantagem absoluta sobre os outros atores. Nesta ciberconfiguração, a importância do que as comunidades locais fazem é diluída, desde que não sejam elas que desenvolvem e controlam as tecnologias da realidade virtual. Infelizmente, essas tecnologias são atualmente altamente inovadoras e utilizam tecnologias de ponta que exigem investimentos significativos que estão nas mãos das maiores corporações globais e não há nenhuma tendência discernível em outra direção.

Como uma implicação geral dos impactos das ciberconfigurações da experiência turística na esfera 
das comunidades locais, é indispensável que elas considerem e atuem de forma rápida e estratégica para evitar ceder o controle de tecnologias que aproveitam seu patrimônio biocultural nas mãos de outros ou daqueles que não estão diretamente envolvidos com a comunidade.

\section{REFLEXÕES FINAIS}

conjunto de reflexões realizadas levou à proposta de cenários em campos de ação estratégica, associados a cada uma das três ciberconfigurações da experiência turística para a gestão sustentável do patrimônio biocultural em locais turísticos. Por se tratar de um documento de natureza teórico-conceitual, esta é tanto sua principal contribuição quanto sua principal limitação, pois abre diretamente a necessidade de delinear futuras linhas de pesquisa, que deverão se concentrar tanto na confirmação, refutação ou enriquecimento das propostas aqui apresentadas por meio de estudos de natureza empírica em diferentes contextos e latitudes, como na aplicação prática das propostas na esfera comunitária local, em locais turísticos cujos atores envolvidos, de maneira coletiva se interessem na gestão sustentável de seu patrimônio biocultural.

Em termos gerais, ao delinear as características e implicações práticas de cada uma das três ciberconfigurações, torna-se evidente que os sítios turísticos em geral e em particular cada campo de ação estratégica moldando em torno de cada manifestação do patrimônio biocultural devem fazer um investimento deliberado para se beneficiar da tecnologia.

Entre as três ciberconfigurações, a que exigiria em princípio menos investimento, talvez seja a $\mathrm{HC}$, depois seria a RA e finalmente a que exige maiores esforços de investimento em desenvolvimento tecnológico é a RV. Obviamente, quando se escolhe, como na maioria dos destinos turísticos atuais, uma combinação das três ciberconfigurações, o que implica uma maior participação de especialistas tanto para a produção das experiências quanto para 0 desenvolvimento tecnológico associado a elas.

Nem todos os destinos turísticos do mundo estão igualmente preparados para realizar esta transformação, mas mesmo que não fossem movidos por sua própria decisão, é muito provável que sejam arrastados para ela pela pressão da tendência global, tanto dos mercados turísticos quanto das forças da globalização capitalista. Assim, a principal implicação destas reflexões seria que não deveria demorar muito para que os atores sociais nos destinos turísticos reconhecessem a tendência, a entendessem da melhor forma possível e agissem localmente de acordo.

Isto traz consigo um impacto imediato na necessidade de pessoal mais capacitado, profissionais com foco no uso intensivo de novas tecnologias, que também têm a visão de respeitar seu ambiente, costumes locais e ancestrais, bem como especialmente aqueles que não querem ou preferem evitar o uso da tecnologia em suas viagens ou em geral nas suas vidas. Uma reeducação completa neste aspecto é muito provavelmente necessária, mas isto seria obviamente o tema de outro estudo.

\section{REFERÊNCIAS}

Adhikari, A., \& Bhattacharya, S. (2016). Appraisal of literature on customer experience in tourism sector: review and framework. Current Issues in Tourism, 19(4), 296-321. https://doi.org/10.1080/13683500.2015.1082538

Agnoletti, M., \& Rotherham, I. D. (2015). Landscape and biocultural diversity. Biodiversity and Conservation, 24(13), 3155-3165. https://doi.org/10.1007/s10531015-1003-8

Bec, A., Moyle, B., Timms, K., Schaffer, V., Skavronskaya, L., \& Little, C. (2019). Management of immersive heritage tourism experiencs: A conceptual model. Tourism Management, 72(November 2018), 117120. https://doi.org/10.1016/j.tourman.2018.10.033

Berger, P., \& Luckmann, T. (1967). The social construction of knowledge: A treatise in the sociology of knowledge. St. Ives: Penguin.

Bogicevic, V., Seo, S., Kandampully, J. A., Liu, S. Q., \& Rudd, N. A. (2019). Virtual reality presence as a preamble of tourism experience: The role of mental imagery. Tourism Management, 74(February), 55-64. https://doi.org/10.1016/j.tourman.2019.02.009

Boksberger, P., \& Akinsola, A. (2011). Blending Information and Communication Technology and Tourism-an Explorative Study of the Impact of Mobile Communication Technology on Tourism Experience. In CAUTHE 2011: National Conference: Tourism: Creating a Brilliant Blend. Adelaide: CAUTHE National Conference.

Boorstin, D. J. (1964). The Image: A Guide to Pseudo-Events in America: Daniel J. Boorstin: New York, USA.: Vintage.

Bourdieu, P., \& Wacquant, L. J. D. (1992). An invitation to reflexive sociology. Chicago: The University of Chicago Press.

Buhalis, D., \& Law, R. (2008). Progress in information technology and tourism management: 20 years on and 10 years after the Internet-The state of eTourism 
research. Tourism Management, 29, 609-623. https://doi.org/10.1016/j.tourman.2008.01.005

Buhalis, D., \& O'Connor, P. (2005). Information communication technology revolutionizing tourism. Tourism Recreation Research, 30(3), 7-16.

Calleja, C. C., \& González, A. (2018). Estudio de la construcción social de las experiencias turísticas de interés y de ruptura desde la metáfora dramatúrgica de Erving Goffman. ROTUR: Revista de Ocio y Turismo, 12(1),

29. https://doi.org/10.17979/rotur.2018.12.1.3424

Campos, A. C., Mendes, J., Valle, P. O. do, \& Scott, N. (2015). Co-creation of tourist experiences: a literature review. Current Issues in Tourism, 21(4), 369-400. https://doi.org/10.1080/13683500.2015.1081158

Cheer, J. M., \& Lew, A. A. (2018). Tourism, Resilience and Sustainability. Adapting to Social, Political and Economic Change. London: Routledge.

Chen, H., \& Rahman, I. (2018). Cultural tourism: An analysis of engagement, cultural contact, memorable tourism experience and destination loyalty. Tourism Management Perspectives, 26(October 2017), 153163. https://doi.org/10.1016/j.tmp.2017.10.006

CISCO. (2015). The Zettabyte Era: Trends and Analysis. Cisco, (May 2015), 1-29.

CISCO. (2016). Collaboration in the Age of HyperConnectivity - Cisco. CISCO India. Retrieved from http://www.cisco.com/c/en_in/about/thoughtleadership/coll-age-hyper-connectivity.html

Coghlan, A., \& Carter, L. (2020). Serious games as interpretive tools in complex natural tourist attractions. Journal of Hospitality and Tourism Management, 42(February), 258-265. https://doi.org/10.1016/j.jhtm.2020.01.010

Cohen, E. (1979). A phenomenology of tourist experiences. Sociology. 13(2), 179-201. https://doi.org/doi: 10.1177/003803857901300203

CONACYT. (2015). Ficha pública del proyecto: 220468. Mexico. Retrieved from https://www.conacyt.gob.mx/index.php/sni/fichas/fi chas-publicas-2015/11411-ficha-publica-2204682/file

Currás, R., Ruiz, C., Sanchez, I., \& Sanz, S. (2017). Determinantes de la retención de clientes en los entornos virtuales. El rol del riesgo percibido en el contexto de los servicios turísticos. Spanish Journal of Marketing - ESIC, 21(2), 131-145. https://doi.org/10.1016/j.sjme.2017.07.002

da Costa Mendes, J., Oom do Valle, P., Guerreiro, M. M., \& Albino Silva, J. (2010). The tourist experience: Exploring the relationship between tourist satisfaction and destination loyalty. Tourism Original Scientific Paper, 58(2), 111-126. Retrieved from http://hrcak.srce.hr/59323

de Bruin, A., \& Jelinčić, D. A. (2016). Toward extending creative tourism: participatory experience tourism. Tourism Review, 71(1), 57-66. https://doi.org/10.1108/16605371111188731

Dickinson, J. E., Ghali, K., Cherrett, T., Speed, C., Davies, N., \& Norgate, S. (2014). Tourism and the smartphone app: capabilities, emerging practice and scope in the travel domain. Current Issues in Tourism, 17(1), 84-101. https://doi.org/10.1080/13683500.2012.718323

DiMaggio, P. J., \& Powell, W. W. (1983). The Iron Cage Revisited: Institutional Isomorphism and Collective Rationality in Organizational Fields. American Sociological Review, 48(2), 147. https://doi.org/10.2307/2095101

Du Cros, H., \& McKercher, B. (2015). Cultural tourism (2a ed.). London: Routledge.

Eide, D., Fuglsang, L., \& Sundbo, J. (2017). Management challenges with the maintenance of tourism experience concept innovations: Toward a new research agenda. Tourism Management, 63, 452463. https://doi.org/10.1016/j.tourman.2017.06.029

Egger, R. (2010). Theorizing Web 2.0 Phenomena in Tourism: A Sociological Signpost. Information Technology \& Tourism, 12(2), 125-137. https://doi.org/10.3727/109830510X128879710026 66

Elands, B. H. M., \& Lengkeek, J. (2012). The tourist experience of out-there-ness: Theory and empirical research. Forest Policy and Economics, 19, 31-38. https://doi.org/10.1016/j.forpol.2011.11.004

Estaregue, D., Schmidt Alves Díaz Merino, G., Díaz Merino, E. A., \& Matos Goncalves, M. (2017). Design experiencial no turismo: uma revisão integrativa sobre o tema. Revista Iberoamericana de TurismoRITUR, 7(1), 85-100. https://doi.org/10.2436/20.8070.01.47

Fligstein, N. (1996). Markets as Politics: A Political-Cultural Approach to Market Institutions. American Sociological Review, 61(4), 656-673. Retrieved from http://www.jstor.org/stable/2096398

Fligstein, N. (2001). The Architecture of Markets: An Economic Sociology of Twenty-First-Century Capitalist Societies. Princeton: Princeton University Press.

Fligstein, N., \& McAdam, D. (2011). Toward a General Theory of Strategic Action Fields. Sociological Theory, 29(1), 1-26. https://doi.org/10.1111/j.14679558.2010.01385.x

Fligstein, N., \& McAdam, D. (2012). A Theory of Fields. London: Oxford University Press. https://doi.org/10.1093/acprof:oso/9780199859948 .001 .0001

Frochot, I., \& Wided, B. (2013). Marketing and Designing the Tourist Experience. Oxford: Goodfellow Publishers Limited.

García, A. (2008). Patrimonio Cultural : Diferentes Perspectivas. Arqueoweb. Revista Sobre Arqueologia En Internet, 9(2), 1-36.

Garay, L. (2019). \#Visitspain. Breaking down affective and cognitive attributes in the social media construction of the tourist destination image. Tourism Management 
Perspectives, 100560. https://doi.org/10.1016/j.tmp.2019.100560

Gardiner, S., \& Scott, N. (2018). Destination Innovation Matrix: A framework for new tourism experience and market development. Journal of Destination Marketing and Management, 10(July), 122-131. https://doi.org/10.1016/j.jdmm.2018.07.002

Gavin, M. C., McCarter, J., Mead, A., Berkes, F., Stepp, J. R., Peterson, D., \& Tang, R. (2015). Defining biocultural approaches to conservation. Trends in Ecology \& Evolution, 30(3), 140-145. https://doi.org/10.1016/j.tree.2014.12.005

Gelter, H. (2010). Total experience management - a conceptual model for transformational experiences within tourism. In The Nordic Conference on Experience 2008. Research, Education and Practice in Media (pp. 46-78). Vaasa: Tritonia.

Gobierno de la Ciudad de México. (2020). El C5 de la CDMX. Retrieved May 15, 2020, from https://www.c5.cdmx.gob.mx/dependencia/acercade/el-c5-de-la-cdmx

Goffman, E. (1986). Frame Analysis. An Essay on the Organization of Experience. Boston: Northeastern University Press.

González, A. (2009). El Turismo desde un Enfoque de Sociología Constructivista. Teoría y Praxis, 6(6), 107122.

González, A. (2017a). Transformaciones espaciotemporales inducidas por las TIC en la experiencia turística: reflexiones desde el construccionismo social. Anais Brasileiros de Estudos Turísticos, 7(1), 23-34.

González, A. (2017b). Construcción social de la experiencia turística (1st ed.). Madrid: Bubok Publishing S.L.

González, A. (2018). Construcción colectiva de la experiencia turística para la sociedad anfitriona: una mirada desde el sur. Revista Latinoamericana Turismologia, 4(1), 34-51.

Govers, R. (2005). Virtual Tourism Destination Image: Glocal identities constructed, perceived and experienced. Rotterdam: Erasmus Research Institute of Management. Retrieved from http://repub.eur.nl/handle/6981

Gretzel, U., \& Jamal, T. (2009). Conceptualizing the creative tourist class: Technology, mobility, and tourism experiences. Tourism Analysis, 14(4), 471-481. https://doi.org/10.3727/108354209X125962871142 19

Guttentag, D. A. (2010). Virtual reality: Applications and implications for tourism. Tourism Management, 31(5), $637-651$. https://doi.org/10.1016/j.tourman.2009.07.003

Hans, R. T. (2014). Using a biometric system to check-in and check-out luggage at airports. In 2014 International Symposium on Biometrics and Security Technologies (ISBAST) (pp. 63-66). Kuala Lumpur: IEEE. https://doi.org/10.1109/ISBAST.2014.7013095

He, M., Li, J., Li, J., \& Chen, H. (2019). A comparative study on the effect of soundscape and landscape on tourism experience. International Journal of Tourism Research, 21(1), 11-22. https://doi.org/10.1002/jtr.2237

He, Z., Wu, L., \& Li, X. (Robert). (2018). When art meets tech: The role of augmented reality in enhancing museum experiences and purchase intentions. Tourism Management, 68, 127-139. https://doi.org/10.1016/j.tourman.2018.03.003

Huang, Y. C., Backman, K. F., Backman, S. J., \& Chang, L. L. (2015). Exploring the implications of virtual reality technology in tourism marketing: an integrated research framework. International Journal of Tourism Research, 13. https://doi.org/10.1002/jtr.2038

Hyundai Motor Mexico. (2020). Explore Teotihuacan. Retrieved May 15, 2020, from https://apps.apple.com/mx/app/exploreteotihuacan/id1450546445

INAH. (2012). Recorrido virtual Museo Regional de Guanajuato. Retrieved from https://www.inah.gob.mx/paseos/museoregionalgt $\mathrm{o} /$

INAH. (2020). Paseo virtual Chichen Itzá. Retrieved May 15, 2020, from https://www.inah.gob.mx/paseos/chichen/

Jackson, M. S., White, G. N., \& Schmierer, C. L. (1996). Tourism experiences within an attributional framework. Annals of Tourism Research, 23(4), 798810. https://doi.org/10.1016/0160-7383(96)00003-5

Jansson, A. (2007). A sense of tourism: new media and the dialectic of encapsulation/decapsulation. Tourist Studies, 7(1), 5-24. https://doi.org/10.1177/1468797607079799

Jennings, G., \& Polovitz N., N. (2006). Quality tourism experiences. Burlington: Elsevier ButterworthHeinemann.

Jung, T., \& Han, D. (2014). Augmented Reality ( AR ) in Urban Heritage Tourism 1 Introduction 2 Writing Style. EReview of Tourism Research, 5, 1-6.

Jurowski, C. (2009). An examination of the four realms of tourism experience theory. In International CHRIE Conference-Refereed Track (pp. 1-8). Amherst: University of Massachusetts. https://doi.org/ISBN\#O9746470-8-X

Keckes, A., \& Tomicic, I. (2017). Augmented Reality in Tourism - Research and Applications Overview. Interdisciplinary Description of Complex Systems, 15(1), 157-167. https://doi.org/10.7906/indecs.15.2.5

Kim, J.-H. (2014). The antecedents of memorable tourism experiences: The development of a scale to measure the destination attributes associated with memorable experiences. Tourism Management, 44, 34-45. https://doi.org/10.1016/j.tourman.2014.02.007

Kim, M. J., \& Hall, C. M. (2019). A hedonic motivation model in virtual reality tourism: Comparing visitors and nonvisitors. International Journal of Information 
Management, 46(July 2018), 236-249. https://doi.org/10.1016/j.jijnfomgt.2018.11.016

Kounavis, C. D., Kasimati, A. E., \& Zamani, E. D. (2012). Enhancing the tourism experience through mobile augmented reality: Challenges and prospects. International Journal of Engineering Business Management, 4, 1-6. https://doi.org/10.5772/51644

Korstanje, M. E., \& George, B. P. (2015). Understanding the Sociological Roots of "No-Shows" in Technology Mediated Transactions in Tourism. E-Review of Tourism Research (ERTR), 1166(5), 71-82.

Laplante, M. (1996). L'expérience touristique contemporaine: fondements sociaux et culturels. Quebec: Universite du Quebec.

Lee, H., Jung, T. H., tom Dieck, M. C., \& Chung, N. (2019). Experiencing immersive virtual reality in museums. Information and Management, (October), 103229. https://doi.org/10.1016/j.im.2019.103229

Lengkeek, J. (2001). Leisure Experience and Imagination. Rethingking Cohen's Modes of Tourist Experience. International Sociology, 16(2), 173-184.

Li, C., Guo, S., Wang, C. L., \& Zhang, J. (2019). Veni, vidi, vici: The impact of social media on virtual acculturation in tourism context. Technological Forecasting and Social Change, 145 (November 2017), 513-522. https://doi.org/10.1016/j.techfore.2019.01.013

Lin, L. P. (Lynn), Huang, S. C. (Lucy), \& Ho, Y. C. (2020). Could virtual reality effectively market slow travel in a heritage destination? Tourism Management, 78(December 2019), 104027. https://doi.org/10.1016/j.tourman.2019.104027

Lin, H., Zhang, M., Gursoy, D., \& Fu, X. (2019). Impact of tourist-to-tourist interaction on tourism experience: The mediating role of cohesion and intimacy. Annals of Tourism Research, 76(March), 153-167. https://doi.org/10.1016/j.annals.2019.03.009

Liu, Y., Li, M., \& Xiao, H. (2013). A Model of Tourist Experience. In The 18 th Annual Graduate Education and Graduate Student Research Conference in Hospitality and Tourism (p. 35). Retrieved from http://conferences.wsu.edu/conferences/hospitality /pdf/ConferenceProceedings.pdf\#page $=56$

MacCannell, D. (1973). Staged authenticity: Arrangements of social space in tourist settings. American Journal of Sociology, 79(3), 589-603. Retrieved from http://www.jstor.org/stable/2776259

Majboub, W. (2014). Co-creation of Value or Co-creation of Experience? Interrogations in the Field of Cultural Tourism. International Journal of Safety and Security in Tourism, 7(7), 12-31.

Martin, J. L. (2003). What Is Field Theory? American Journal of Sociology, 109(1), 1-49. https://doi.org/10.1086/375201

Martins, J., Gonçalves, R., Branco, F., Barbosa, L., Melo, M., \& Bessa, M. (2017). A multisensory virtual experience model for thematic tourism: A Port wine tourism application proposal. Journal of Destination
Marketing and Management, 6(2), 103-109. https://doi.org/10.1016/j.jdmm.2017.02.002

McAdam, D. (1982). Political Process and the Development of Black Insurgency, 1930 - 1970 (2nd ed.). Chicago: The University of Chicago Press.

Morgan, M., Lugosi, P., \& Ritchie, J. R. B. R. (2010). The Tourism and Leisure Experience, Consumer and Managerial Perspectives. Bristol: Channel View Publications.

Moscardo, G. (2010). The shaping of tourist experience. The importance of stories and themes. In M. Morgan, P. Lugosi, \& J. R. B. R. Ritchie (Eds.), The tourism and leisure experience. Consumer and Managerial Perspectives. Channel View Publications.

Muñoz, A. I., Fuente, L., \& Fayos-Solà, E. (2012). Turismo como instrumento de desarrollo: Una visión alternativa desde factores humanos, sociales e institucionales. PASOS Revista de Turismo y Patrimonio Cultural, 10(5), 437-469.

NASA. (2017). Take a Walk on Mars -- in Your Own Living Room. Retrieved May 15, 2020, from https://www.nasa.gov/feature/jpl/take-a-walk-onmars-in-your-own-living-room

Neuhofer, B., Buhalis, D., \& Ladkin, A. (2014). A Typology of Technology-Enhanced Tourism Experiences. International Journal of Tourism Research, 16(4), 340350. https://doi.org/10.1002/jtr.1958

Obenour, W., Patterson, M., Pedersen, P., \& Pearson, L. (2006). Conceptualization of a meaning-based research approach for tourism service experiences. Tourism Management, 27(1), 34-41. https://doi.org/10.1016/j.tourman.2004.07.008

Oh, H., Fiore, a. M., \& Jeoung, M. (2007). Measuring Experience Economy Concepts: Tourism Applications. Journal of Travel Research, 46(2), 119132. https://doi.org/10.1177/0047287507304039

Okazaki, S., Campo, S., Andreu, L., \& Romero, J. (2015). A Latent Class Analysis of Spanish Travelers' Mobile Internet Usage in Travel Planning and Execution. Cornell Hospitality Quarterly, 56(2), 191-201. https://doi.org/10.1177/1938965514540206

Özdemir, E., \& Kilıç, S. (2018). Augmented Reality. En J. Rodrigues, C. Ramos, P. Cardoso, C. Henriques, T. Adão, D. Agapito, ... C. Gonçalves (Eds.), Handbook of Research on Technological Developments for Cultural Heritage and eTourism Applications (pp. 54-71). Hershey: IGI Global. https://doi.org/10.4018/978-15225-2927-9.ch003

Özkul, E., \& Kumlu, S. T. (2019). Augmented Reality Applications in Tourism. International Journal of Contemporary Tourism Research, (December 2019), 107-122. https://doi.org/10.30625/ijctr.625192

Prahalad, C. K., \& Ramaswamy, V. (2004). Co-creation experiences: the next practice in value creation. Journal of Interactive Marketing, 18(3), 5-15. https://doi.org/10.1002/dir.20015

Prebensen, N., Chen, J., \& Uysal, M. (2014). Creating Tourist 
Experience Value in Tourism. Oxfordshire: CABI.

Quan, S., \& Wang, N. (2004). Towards a structural model of the tourist experience: an illustration from food experiences in tourism. Tourism Management, 25, 297-305. https://doi.org/10.1016/S02615177(03)00130-4

Red DTI. (2020). Destino Turístico Inteligente. Retrieved May 15, 2020, from https://www.destinosinteligentes.es/

Ryan, C. (2002). The tourist experience. London: Cengage Learning Emea.

Salazar, B. R., González, A., \& Macías, A. R. (2020). El turismo cultural y sus construcciones sociales como contribución a la gestión sostenible de los destinos turísticos. Revista Rosa Dos Ventos - Turismo e Hospitalidade, 12(2), 406-428. https://doi.org/10.18226/21789061.v12i2p406

Sfandla, C., \& Bjork, P. (2012). Tourism Experience Network: Co-creation of Experiences in Interactive Processes. International Journal of Tourism Research, 15(5), 495506. https://doi.org/10.1002/jtr.1892

Sharpley, R., \& Stone, P. R. (2011). Tourist Experience: Contemporary Perspectives. London: Routledge.

Sharpley, R., \& Stone, P. R. (2012). Contemporary Tourist Experience, Concepts and Consequences. London: Routledge.

Sheldon, P. J. (2004). eTourism: Information Technology for Strategic Tourism Management. Annals of Tourism Research, 31(3), 740-741. https://doi.org/10.1016/j.annals.2004.03.002

Small, J., \& Darcy, S. (2011). Understanding tourist experience through embodiment: The contribution of critical tourism and disability studies. In D. Buhalis \& S. Darcy (Eds.), Accessible tourism: concepts and issues (pp. 73-97). London: Channel View Publications.

Sugathan, P., \& Ranjan, K. R. (2019). Co-creating the tourism experience. Journal of Business Research, 100 (December 2017), 207-217. https://doi.org/10.1016/j.jbusres.2019.03.032

Teisl, M. F., Noblet, C. L., Corey, R. R., \& Giudice, N. A. (2018). Seeing clearly in a virtual reality: Tourist reactions to an offshore wind project. Energy Policy, 122 (August), 601-611. https://doi.org/10.1016/j.enpol.2018.08.018

Tussyadiah, I. P. (2014). Toward a Theoretical Foundation for Experience Design in Tourism. Journal of Travel Research, 53(5), 543-564. https://doi.org/10.1177/0047287513513172

Tussyadiah, I. P., \& Fesenmaier, D. R. (2009). Mediating Tourist Experiences. Access to Places via Shared Videos. Annals of Tourism Research, 36(1), 24-40. https://doi.org/10.1016/j.annals.2008.10.001

Tussyadiah, I., \& Miller, G. (2019). Nudged by a robot: Responses to agency and feedback. Annals of Tourism Research, 78(July). https://doi.org/10.1016/j.annals.2019.102752

Tussyadiah, I. P., Wang, D., Jung, T. H., \& tom Dieck, M. C.
(2018). Virtual reality, presence, and attitude change: Empirical evidence from tourism. Tourism Management, 66, 140-154. https://doi.org/10.1016/j.tourman.2017.12.003

Uriely, N. (2005). The tourist experience. Conceptual developments. Annals of Tourism Research, 32(1), 199-216. https://doi.org/10.1016/j.annals.2004.07.008

Uriely, N., Yonay, Y., \& Simchai, D. (2002). Backpacking experiences. Annals of Tourism Research, 29(2), 520538. https://doi.org/10.1016/S0160-7383(01)00075$\underline{5}$

Vada, S., Prentice, C., \& Hsiao, A. (2019). The influence of tourism experience and well-being on place attachment. Journal of Retailing and Consumer Services, 47(December 2018), 322-330. https://doi.org/S0969698918310245

Wang, D., \& Fesenmaier, D. R. (2013). Transforming the Travel Experience: The Use of Smartphones for Travel. In L. Cantoni \& Z. Xiang (Eds.), Information and Communication Technologies in Tourism (pp. 58-69). Berlin: Springer. https://doi.org/10.1007/978-3-64236309-2_6

Wang, D., \& Xiang, Z. (2012). The New Landscape of Travel: A Comprehensive Analysis of Smartphone Apps. In M. Fuchs, F. Ricci, \& L. Cantoni (Eds.), Information and communication technologies in tourism 2012 (pp. 308-320). Vienna: Springer. https://doi.org/10.1007/978-3-7091-1142-0_27

Wang, D., Xiang, Z., \& Fesenmaier, D. R. (2016). Smartphone Use in Everyday Life and Travel. Journal of Travel Research, 55(1), 52-63. https://doi.org/10.1177/0047287514535847

WCED. (1987). Report of the World Commission on Environment and Development: Our common future. Oslo. Retrieved from http://www.askforce.org/web/Sustainability/Brundtland-OurCommon-Future-1987-2008.pdf

Wei, W., Qi, R., \& Zhang, L. (2019). Effects of virtual reality on theme park visitors' experience and behaviors: A presence perspective. Tourism Management, 71(August 2018), 282-293. https://doi.org/10.1016/j.tourman.2018.10.024

Wickens, E. (2002). The sacred and the profane. Annals of Tourism Research, 29(3), 834-851. https://doi.org/10.1016/S0160-7383(01)00088-3

Wong, I. K. A., Liu, D., Li, N., Wu, S., Lu, L., \& Law, R. (2019). Foodstagramming in the travel encounter. Tourism Management, 71(August 2018), 99-115. https://doi.org/10.1016/j.tourman.2018.08.020

Xiao, W., Mills, J., Guidi, G., Rodríguez, P., Gonizzi, S., \& González, D. (2018). Geoinformatics for the conservation and promotion of cultural heritage in support of the UN Sustainable Development Goals. ISPRS Journal of Photogrammetry and Remote Sensing, 142, 389-406. https://doi.org/10.1016/j.isprsjprs.2018.01.001 
Zeng, G., Cao, X., Lin, Z., \& Xiao, S. H. (2020). When online reviews meet virtual reality: Effects on consumer hotel booking. Annals of Tourism Research, 81(December 2019), 102860. https://doi.org/10.1016/j.annals.2020.102860

Zgolli, S., \& Zaiem, I. (2017). Customer-to-customer interaction in tourism experience: Moderating role of nationality. Arab Economic and Business Journal, 12(1),

44-56. https://doi.org/10.1016/j.aebj.2017.03.001

\section{AGRADECIMENTOS}

Ao CONACYT e ao Programa Delfín, pelo financiamiento em forma de bolsas para vários participantes nas investigações que dão sustento ao presente texto.

Processo Editorial / Editorial Process / Proceso Editorial

Editor Chefe / Editor-in-chief / Editor Jefe: PhD Thiago D. Pimentel (UFJF).

Recebido / Received / Recibido: 11.06.2020; Revisado / Revised / Revisado: 07.12.2020; Aprovado / Approved / Aprobado:

17.12. 2020; Publicado / Published / Publicado (online): 26.12.2020.

Tradução do original do autor / Translation of author's original paper / Texto traducido de la versión original del autor. 